\title{
Erratum to: The risk of cancer in patients with rheumatoid arthritis taking tumor necrosis factor antagonists: a nationwide cohort study
}

\author{
Chun-Ying Wu 1,2,3,4, Der-Yuan Chen 1,4,5,6, Jui-Lung Shen ${ }^{7}$, Hsiu J. Ho ${ }^{2}$, Chih-Chiang Chen ${ }^{8}$, Ken N. Kuo 9,10,
} Han-Nan Liu ${ }^{8}$, Yun-Ting Chang ${ }^{1,8^{*}+}$ and Yi-Ju Chen ${ }^{1,7^{*+}}$

Unfortunately, after publication of this article [1], it was noticed that there was an error in the funding information located in the Acknowledgements section. The support grants for the study should instead be listed as TCVGH-1026802C and TCVGH-1026801B, seen in the correct Acknowledgements below.

\section{Reference}

1. Chun-Ying W, Der-Yuan C, Jui-Lung S, Ho HJ, Chih-Chiang C, Kuo KN, Han-Nan L, Yun-Ting C, Yi-Ju C. The risk of cancer in patients with rheumatoid arthritis taking tumor necrosis factor antagonists: a nationwide cohort study. Arthritis Res Ther. 2014;16:449. doi:10.1186/ s13075-014-0449-5.

\begin{abstract}
Acknowledgements
This study has been supported by grants from Taichung Veterans General Hospital (TCVGH-1026802C and TCVGH-1026801B.) and Taipei Veterans General Hospital (R-1100401 and R-11004-02). This study is based on data from the National Health Insurance Research Database provided by the Bureau of National Health Insurance, Department of Health and managed by the National Health Research Institute. The interpretations and conclusions contained herein do not represent those of the Bureau of National Health Insurance, Department of Health or the National Health Research Institute. Yi-Ju Chen has full access to all of the data in the study and takes responsibility for the integrity of the data and the accuracy of the data analysis.
\end{abstract}

\begin{abstract}
Author details
${ }^{1}$ Faculty of Medicine, School of Medicine, National Yang-Ming University, Taipei, Taiwan. ${ }^{2}$ Division of Gastroenterology, Taichung Veterans General Hospital, Taichung, Taiwan. ${ }^{3}$ Department of Public Health and Graduate Institute of Clinical Medicine, China Medical University, Taichung, Taiwan. ${ }^{4}$ Department of Life Sciences, National Chung-Hsing University, Taichung, Taiwan. ${ }^{5}$ Department of Allergy, Immunology and Rheumatology, Taichung Veterans General Hospital, Taichung, Taiwan. Institute of Microbiology and Immunology, Chung-Shan Medical University, Taiwan, Taiwan. ${ }^{7}$ Department of Dermatology, Taichung Veterans General Hospital, Taichung, Taiwan. ${ }^{8}$ Department of Dermatology, Taipei Veterans General Hospital, Taipei, Taiwan. ${ }^{9}$ College of Medicine, Taipei Medical College, Taipei, Taiwan. ${ }^{10}$ Institute of Population Health Sciences, National Health Research Institutes, Miaoli, Taiwan
\end{abstract}

Received: 10 May 2016 Accepted: 11 May 2016

Published online: 17 May 2016

\footnotetext{
* Correspondence: ytchang@vghtpe.gov.tw; yjchenmd@vghtc.gov.tw ${ }^{\dagger}$ Equal contributors

${ }^{1}$ Faculty of Medicine, School of Medicine, National Yang-Ming University, Taipei, Taiwan

Full list of author information is available at the end of the article
}

\footnotetext{
Submit your next manuscript to BioMed Central and we will help you at every step:

- We accept pre-submission inquiries

- Our selector tool helps you to find the most relevant journal

- We provide round the clock customer support

- Convenient online submission

- Thorough peer review

- Inclusion in PubMed and all major indexing services

- Maximum visibility for your research
}

Submit your manuscript at www.biomedcentral.com/submit (c) 2016 Wu et al. Open Access This article is distributed under the terms of the Creative Commons Attribution 4.0 International License (http://creativecommons.org/licenses/by/4.0/), which permits unrestricted use, distribution, and reproduction in any medium, provided you give appropriate credit to the original author(s) and the source, provide a link to the Creative Commons license, and indicate if changes were made. The Creative Commons Public Domain Dedication waiver (http://creativecommons.org/publicdomain/zero/1.0/) applies to the data made available in this article, unless otherwise stated. 